\title{
Perencanaan Konstruksi Sistem Hidrolik pada Clamping Unit Untuk Mesin Cetakan Injeksi Plastik Kapasitas 700 Ton di PT.XXX
}

\author{
Prayoga Saeful Amran ${ }^{1, a)}$, Dr. Ing. Putu M Santika ${ }^{2, b)}$, Ir. Maradu Sibarani, M.Si ${ }^{3, c)}$ \\ 1,2Program Studi Teknik Mesin ITI, \\ Jl. Raya Puspiptek Serpong, Tangerang Selatan-Banten, Indonesia, 15320 \\ ${ }^{3}$ Pusat Rekayasa Perangkat Nuklir, BATAN, \\ Jl. Raya Puspiptek Serpong, Tangerang Selatan-Banten, Indonesia, 15320 \\ a) machine0061@yahoo.com ${ }^{\text {b) }}$ putumsantika190851@gmail.com, ${ }^{\text {c) }}$ sibaranimaradu@yahoo.com
}

\begin{abstract}
Abstrak
Mesin injeksi plastk sudah digunakan dari tahun 90-an hingga sekarang, karena prosesnya yang cepat dan tidak memakan waktu yang lama sehingga mesin injeki plastik ini sering dijadikan mass production. Mesin injeksi plastik ini salah satunya digerakkan oleh sistem hidrolik pada mold clamp unit. Yang berfungsi untuk menekan dan menahan mold platen agar pada saat penginjeksian material kedalam cetakan tidak bergerak ataupun terbuka. Perancangan ini bertujuan untuk mengetahui dan menghitung bagian-bagian seperti batang pengikat (tie bar), silinder, laju aliran fluida dalam silinder, kapasitas pompa, katup-katup, maupun volume tangki. Sistem hidrolik di mold clamping unit ini harus mampu menahan gaya lebih dari 700 ton.
\end{abstract}

Kata Kunci: mold clamp unit, mesin injeksi plastik, sistem hidrolik

\begin{abstract}
The plastic injection machine has been used from the 90s to the present, because the process is fast and does not take a long time so that the injection plastic machine could be used for mass production. Injection plastic machine is one of them driven by the hydraulic system in the mold clamp unit. Its function is to press and hold the mold platen in order at the time of injection of material into the mold did not move or open. The design aims to determine and calculate the parts such as tie bars, cylinder, mass flow fluids in the cylinder, capacity of pumps, valves, and the volume of the tank. The hydraulic system in the mold clamping unit must be able to withstand the force of more than 700 tons.
\end{abstract}

Keywords: Hydraulic System, Injection Plastic Machine, Mold Clamp Unit

\section{PENDAHULUAN}

Pada era modern dan globalisasi ini, perkembangan teknologi dalam dunia industri sudah sangat pesat, dimana industri-industri sekarang sangat mengandalkan produk-produk secara massal dalam produksinya. Seiring dengan dengan perkembangan waktu banyak yang mengembangkan teknologi-teknologi seperti mesin cetakan secara injeksi pada plastik, ataupun pada perlakuan bahan-bahan lainnya. Saat ini yang kita ketahui bahwa telah banyak perusahan molding (pencetakan) yang berdiri di Indonesia, dari yang lokal maupun dari perusahan luar negri seperti Jepang, India, dan Korea Selatan. Moldingnya pun beranekaragam mulai dari injection molding, blowmold, rotomold, transfer molding, extrusion molding, dan lain-lain.

Mesin cetakan injeksi pun itu sendiri merupakan mesin yang berfungsi untuk membuat dan merubah bentuk pada bahan material plastik seperti PVC, ABS, PP dan lain-lain menjadi bentuk yang dinginkan dengan mempertimbangkan estimasi waktu yang relatif singkat, biaya yang murah, dan memproduksi secara besarbesaran atau massal.
Mesin Injeksi ini mengoptimalisasikan hidrolik dengan tekanan yang tinggi untuk dapat menekan mold cavity dan core, sehingga nozzle dapat menginjeksikan plastik dengan baik. Sebelum plastik di injeksikan kedalam mold melalui nozzle, langkah sebelum material kasar (Contoh: PP, PVC, PE, dsb) masukan kedalam ruang pengering yang disebut dryer, kemudian setelah melakukan proses pengeringan material akan otomatis masuk kedalam barrel, untuk dilakukannya proses heatearisasi untuk membuat material meleleh sebelum di injeksikan dengan tekanan tertentu pada mekanisme sistem hidrolik.

Adapun yang menjadi batasan masalah dalam penelitian dengan judul Perancangan Kontsruksi Sistem Hidrolik pada Clamping Unit Untuk Kapasitas 700 Ton ini adalah:

1. Perancangan Kerja Sistem Hidrolik hanya merancang pada bagian clamping unit.

2. Bagian-bagian yang direncanakan adalah batang pengikat, ulir dan baut, silinder, hidrolik, laju aliran fluida, volume fluida, pipa, daya pompa, dan tangki. 
3. Tidak merancang bagian pompa, motor, dan katupkatup, sehingga hanya menggunakan spesifikasi sesuai standar.

4. Tidak merencanakan dudukan atau bantalan pada tangki maupun pada movable plasten, stationery platen, dan unit injeksi.

Tujuan perancangan ini adalah untuk menganalisis dan memperhitungkan kecepatan, waktu, dan gap pada waktu hidrolik menekan menakan mold dan cavity pada mesin injeksi, dan merancang sistem hidrolik, pompa, saluran-saluran fluida untuk sistem hidrolik, dan kapasitas pada reservoir di PT. XXX.

\section{METODE PERANCANGAN}

Pelaksanaan perancangan ini mengikuti diagram alir yang ditunjukan pada gambar 1 .

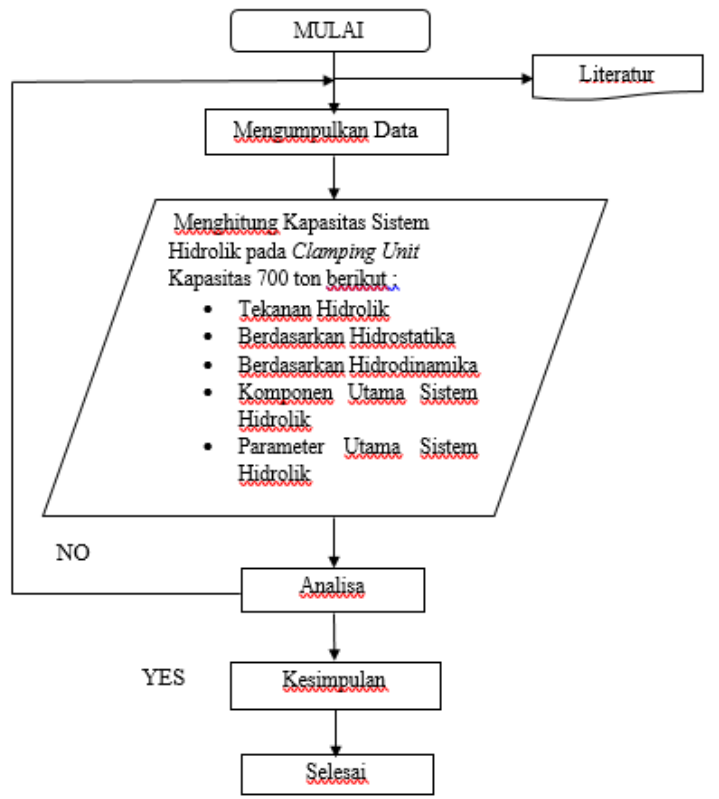

Gambar 1. Diagaram Alir Analisa Kerja Sistem Hidrolik Pada Mesin Injeksi Plastik di PT.XXX

\section{HASIL DAN PEMBAHASAN}

Gambar 2 memperlihatkan bagian-bagian dari mold clamp unit yang direncanakan pada perancangan yakni:

1. Tangki (Reservoir)

2. Pompa dan Motor

3. Check Valve

4. Flow Control Valve

5. Directional Valve

6. Join T

7. Clamp Silinder

8. Ulir dan Mur

9. Batang Pengikat (tie bar)

10. Movable Platen

11. Stationery Platen

12. Saringan

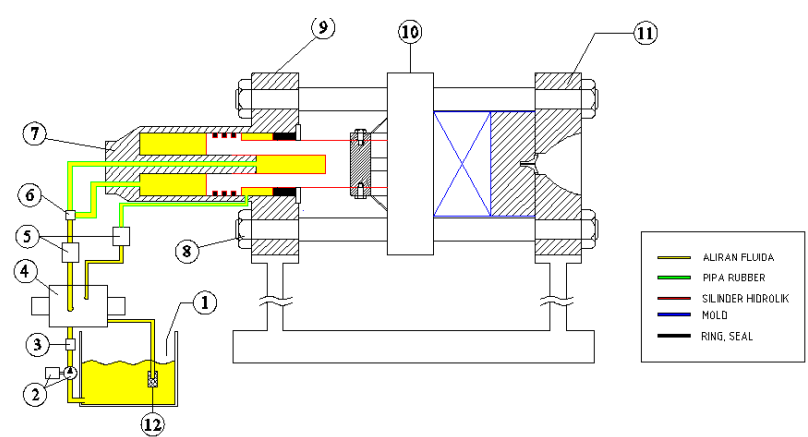

Gambar 2. Skesta Desain Kerja Sistem Hidrolik Mold Clamp Unit

A. Perhitungan beban pada batang pengikat (tie bar)

Mesin selex kapasitas 700 ton kemudian direncanakan 850 ton untuk meningkatkan sf (Safety Factor) dan gaya tekannya.

$$
\mathrm{F}=\frac{\mathbf{8 5 0}}{4}=212,5 \text { ton } / \text { batang pengikat }
$$

Direncanakan diameter batang pengikat

$\mathrm{D}_{1}=3^{1} / 4$ inch $=82,55 \mathrm{~mm}$

$\mathrm{D}_{2}=100 \mathrm{~mm}$

$$
\sigma_{\mathrm{t}}=\frac{F}{A}=\frac{212,5 \text { ton }}{\frac{\pi}{4} 82,55^{2} \mathrm{~mm}}=39,724 \mathrm{~kg} / \mathrm{mm}^{2}
$$

Dimana:

$$
\begin{aligned}
& \sigma_{\mathrm{t}}=\text { Tegangan Tarik }\left(\mathrm{kg} / \mathrm{mm}^{2}\right) \\
& \mathrm{F}=\text { Gaya }(\mathrm{kg}, \mathrm{N}) \\
& \mathrm{A}=\text { Luas Penampang Batang Pengikat }\left(\mathrm{mm}^{2}\right)
\end{aligned}
$$

Menggunakan material SFNCM 110 S dengan kekuatan tarik $120 \mathrm{~kg} / \mathrm{mm}^{2}$ dengan memperhitungkan tegangan izin sebagai berikut:

$$
\begin{aligned}
& \sigma_{\mathrm{t}}<\sigma_{\text {izin }} \rightarrow \sigma_{\text {izin }}=\frac{\sigma_{B}}{S_{f}}=\frac{120 \mathrm{~kg} / \mathrm{mm}^{2}}{3}=40 \mathrm{~kg} / \mathrm{mm}^{2} \\
& \downarrow
\end{aligned}
$$

B. Menghitung Tegangan Pada Ulir Baut Spesifikasi:

- Ulir $=$ Withworth $3 \frac{1}{4}$ inch $\times 3,25$

- Nominal Diameter $=3,25 \mathrm{~mm}$

- $\quad$ Thread per inch (TPI) $=3,25 \mathrm{~mm}$

- $\quad$ Major Diameter (D) (inches) $=3,2500=82,55$

- Depth of Thread $(\mathrm{H})=0,1970=5,003 \mathrm{~mm}$

- $\left(\mathrm{H}_{1}\right)$

$$
=3,337 \mathrm{~mm}
$$

- $\quad$ Efektif Diameter $\left(\mathrm{D}_{2}\right)=3,0530=77,54 \mathrm{~mm}$

- Minor Diameter $\left(\mathrm{D}_{3}\right)=2,8560=72,77 \mathrm{~mm}$

- $\operatorname{Pitch}(\mathrm{P})$ (inches) $=0,3077=7,81 \mathrm{~mm}$

- Root Radius (r) (inches) =0,0423 
Rumus mencari tegangan tarik pada baut [2]:

$\sigma_{\text {aksial }}=\frac{F}{A}=\frac{212500 \mathrm{~kg}}{\frac{\pi}{4} \cdot D . t . z}=\frac{212500 \mathrm{~kg}}{\frac{\pi}{4} .9255 .7 .91 .11}=\mathbf{3 8 , 1 7} \mathrm{kg} / \mathrm{mm}^{2}$

Dimana:

$\mathrm{D}=$ Diameter luar $(\mathrm{mm})$

$\mathrm{A}=$ Luas Penampang Berulir $\left(\mathrm{mm}^{2}\right)$

$\mathrm{t}=$ Pitch $=0,3077=7,81 \mathrm{~mm}$

$\mathrm{z}=11$

$\sigma_{B}=$ Kekuatan Tarik Bahan SFNCM $110 \mathrm{~S}$ adalah 120 $\mathrm{kg} / \mathrm{mm}^{2}$

$\mathrm{S} f=3$

$$
\sigma_{\alpha}=\frac{120}{a}=40 \mathrm{~kg} / \mathrm{mm}^{2}>\sigma_{\mathrm{t}}=38,17 \mathrm{~kg} / \mathrm{mm}^{2}
$$

C. Menghitunng Beban Movable Platen (MP)

Diketahui:

Spesifikasi:

- $\mathrm{MP}=p \times l=780 \mathrm{~mm} \times 780$

- $\quad$ tebal $=200 \mathrm{~mm}$

- $\rho_{(\text {baja })}=7,8 \times 10^{3} \mathrm{~kg} / \mathrm{m}^{3}$

Volume dari suatu material dapat dirumuskan:

$$
\begin{aligned}
\mathrm{V} & =\mathrm{P} \times 1 \times \text { tebal } \\
& =0,78 \mathrm{~m} \times 0,78 \mathrm{~m} \times 0,2 \mathrm{~m}=0,1216 \mathrm{~m}^{3} \\
\mathrm{~W} & =\mathrm{V} \cdot \rho_{(\text {baja })} \\
& =0,1216 \mathrm{~m}^{3} \times 7,8 \cdot 10^{3} \mathrm{~kg} / \mathrm{m}^{3}=948,48 \mathrm{~kg}
\end{aligned}
$$

C1. Menghitung Beban Pada Mold Cavity (MC)

Diketahui:

Spesifikasi:

- $\mathrm{MC}=p \times l=450 \mathrm{~mm} \times 450$

- $\quad$ tebal $=245 \mathrm{~mm}$

- $\rho_{(\text {baja })}=7,8 \times 10^{3} \mathrm{~kg} / \mathrm{m}^{3}$

Volume dari suatu material dapat dirumuskan:

$$
\begin{aligned}
\mathrm{V} & =\mathrm{P} \times 1 \times \text { tebal } \\
& =0,45 \mathrm{~m} \times 0,45 \mathrm{~m} \times 0,245 \mathrm{~m}=0,049 \mathrm{~m}^{3} \\
\mathrm{~W} & =\mathrm{V} \cdot \rho_{(\text {baja })} \\
& =0,049 \mathrm{~m}^{3} \times 7,8 \cdot 10^{3} \mathrm{~kg} / \mathrm{m}^{3}=382,2 \mathrm{~kg}
\end{aligned}
$$

C2. Menghitung Momen Bending

$$
\begin{aligned}
M & =\frac{\left(W_{\text {platen }}+W_{\text {mold }}\right) l}{4} \\
& =\frac{(948,48 \mathrm{~kg}+382,2) 1015 \mathrm{~mm}}{4} \\
& =337,66 \mathrm{~kg} \cdot \mathrm{m}
\end{aligned}
$$

C3. Menghitung Beban Pada Stationery Plate (SP)

Diketahui:

Spesifikasi:
- $\mathrm{SP}=p \times l=450 \mathrm{~mm} \times 450$

- $\quad$ tebal $=245 \mathrm{~mm}$

- $\rho_{(\text {baja })}=7,8 \times 10^{3} \mathrm{~kg} / \mathrm{m}^{3}$

Volume dari suatu material dapat dirumuskan:

$$
\begin{aligned}
\mathrm{V} & =\mathrm{P} \times 1 \times \text { tebal } \\
& =0,45 \mathrm{~m} \times 0,45 \mathrm{~m} \times 0,245 \mathrm{~m} \\
& =0,049 \mathrm{~m}^{3} \\
\mathrm{~W} & =\mathrm{V} \cdot \rho_{(b a j a)} \\
& =0,049 \mathrm{~m}^{3} \times 7,8 \cdot 10^{3} \mathrm{~kg} / \mathrm{m}^{3} \\
& =382,2 \mathrm{~kg}
\end{aligned}
$$

C4. Menghitung Beban Pada Mold Core SP

Diketahui:

Spesifikasi:

- $\mathrm{MCSP}=p \times l=450 \mathrm{~mm} \times 450$

- $\quad$ tebal $=265 \mathrm{~mm}$

- $\rho_{(b a j a)}=7,8 \times 10^{3} \mathrm{~kg} / \mathrm{m}^{3}$

Volume dari suatu material dapat dirumuskan:

$$
\begin{aligned}
\mathrm{V} & =\mathrm{P} \times 1 \times \text { tebal } \\
& =0,45 \mathrm{~m} \times 0,45 \mathrm{~m} \times 0,265 \mathrm{~m} \\
& =0,053 \mathrm{~m}^{3} \\
\mathrm{~W} & =\mathrm{V} \cdot \rho_{(\text {baja })} \\
& =0,053 \mathrm{~m}^{3} \times 7,8 \cdot 10^{3} \mathrm{~kg} / \mathrm{m}^{3} \\
& =413,4 \mathrm{~kg}
\end{aligned}
$$

C5. Analisis Gaya-Gaya Perbatang Pengikat (Tie bar)

$$
\begin{aligned}
\mathrm{F} & =\frac{W_{\text {platen }} \mathrm{MP}+W_{\text {mold }} \mathrm{MP}}{4} \\
& =\frac{984,48 \mathrm{~kg}+382,2 \mathrm{~kg}}{4} \\
& =332,67 \mathrm{~kg} \cdot 9,81 \mathrm{~m} / \mathrm{s}^{2} \\
& =3263,49 \mathrm{~N}
\end{aligned}
$$

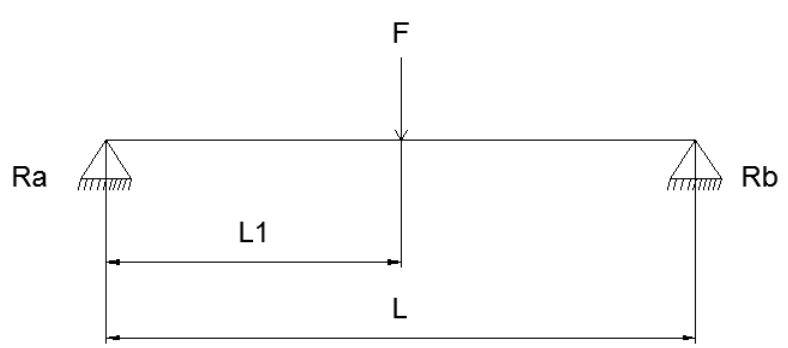

Gambar 3. Analisa Gaya-Gaya Pembebanan

Dimana:

$$
\begin{aligned}
& \mathrm{L}_{1}=580 \mathrm{~mm} \\
& \mathrm{~L}=1215 \mathrm{~mm}
\end{aligned}
$$

$$
\begin{aligned}
\sum \mathrm{F}_{x} & =0 \\
\mathrm{R}_{\mathrm{A}}+\mathrm{R}_{\mathrm{B}} & =\mathrm{F}
\end{aligned}
$$


$\mathrm{R}_{\mathrm{A}}=\mathrm{F}-\mathrm{R}_{\mathrm{B}}$

$\mathrm{R}_{\mathrm{A}}=3263,49 \mathrm{~N}-\mathrm{R}_{\mathrm{B}}$

$\Rightarrow \mathrm{R}_{\mathrm{A}}=3263,49 \mathrm{~N}-1796,563 \mathrm{~N}=1466,927 \mathrm{~N}$

$\sum \mathrm{M}_{\mathrm{A}}=\mathrm{F} \cdot \mathrm{L}_{1}-\mathrm{R}_{\mathrm{B}} \cdot \mathrm{L}$

$\mathrm{R}_{\mathrm{B}}=\frac{\mathrm{F} \cdot \mathrm{L}_{1}}{\mathrm{~L}}=\frac{3763,49 \cdot 580}{1215}=1796,563 \mathrm{~N}$

D. Menghitung Tegangan Pada Baut Piston Silinder

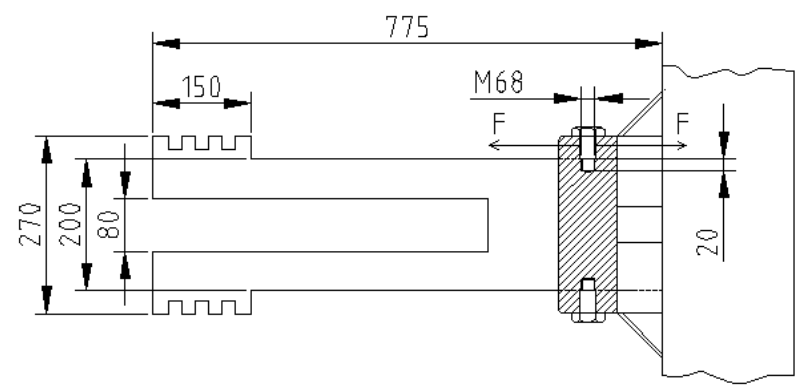

Gambar 4. Piston Silinder

Diperlihatkan pada gambar 4 bahwa gaya $\mathrm{F}$ juga akan menimbulkan tegangan geser pada luas bidang silinder dimana tebal akar ulir luar. Besar tegangan geser ini $\tau_{b}$ $\left(\mathrm{kg} / \mathrm{mm}^{2}\right)$ adalah:

$$
\tau_{b}=\frac{W}{\frac{\pi}{4} . D 1^{2}}<\tau_{b a}
$$

Direncanakan menggunakan ulir M30 dengan kedalaman ulir pada silinder $20 \mathrm{~mm}$.

Dimana:

$$
\begin{aligned}
\sigma_{B} & =\text { Kekuatan Tarik Pada Baut }=80 \mathrm{~kg} / \mathrm{mm}^{2} \\
\mathrm{P} & =\text { Pitch }=6 \mathrm{~mm} \\
\mathrm{H}_{1} & =3,248 \mathrm{~mm} \\
\mathrm{D} & =68 \mathrm{~mm} \\
\mathrm{D}_{2} & =64,103 \mathrm{~mm} \\
\mathrm{D}_{1} & =61,505 \mathrm{~mm} \\
\mathrm{~h} & =\text { kedalaman baut }=20 \mathrm{~mm} \\
\mathrm{k} & =\text { Faktor Ulir Metris }=0,84
\end{aligned}
$$

Luas Penampang Silinder

$$
\begin{aligned}
& \mathrm{A}=\left(\left(\pi \cdot \mathrm{D}_{1} \cdot \mathrm{t}\right)+\left(\pi \cdot \mathrm{D}_{2} \cdot \mathrm{t}_{2}\right)-\left(\pi \cdot \mathrm{D}_{3} \cdot \mathrm{t}_{3}\right)\right) \\
& =((3,14 \cdot 0,27 \cdot 0,15)+(3,14 \cdot 0,20 \cdot 0,625)- \\
& (3,14.0,08 \cdot 0,51)) \\
& =(0,127+0,392)-0,128 \\
& =0,391 \mathrm{~m}^{2}=391000 \mathrm{~mm}^{2} \\
& \tau_{b}=\frac{\text { Wybaut }}{\frac{\pi}{4}, 61,505^{2}}\left(\mathrm{~kg} / \mathrm{mm}^{2}\right) \\
& =\frac{106250 \mathrm{~kg}}{29695 \mathrm{~mm}^{2}}=35,78 \mathrm{~kg} / \mathrm{mm}^{2}
\end{aligned}
$$

Tegangan yang diizinkan adalah $\tau_{b a}=\frac{\sigma_{B}}{a}=\frac{\operatorname{so~kg} / \mathrm{mm}^{2}}{2}=40 \mathrm{~kg} / \mathrm{mm}^{2}>\tau_{b}=35,78 \mathrm{~kg} / \mathrm{mm}^{2}$

E. Menghitung Volume Fluida Pada Silinder Hidrolik
E1. Volume Fluida Pada Saat Mold Menutup

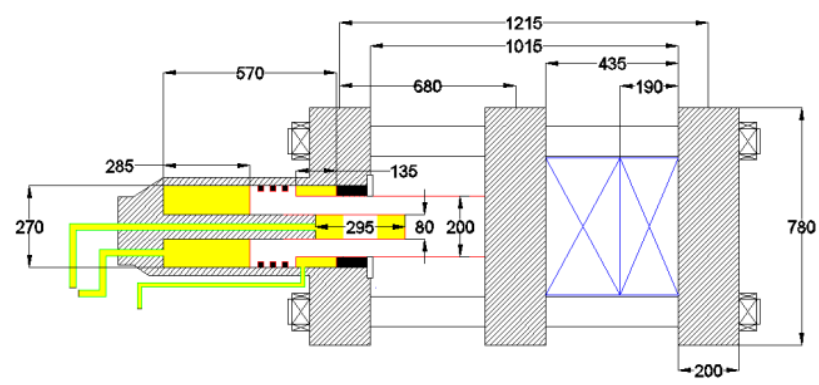

Gambar 5. Aliran Fluida Pada Saat Mold Menutup

$$
\begin{aligned}
\mathrm{V}_{\mathrm{c}} & =\left(\frac{\pi}{4} \mathrm{D}_{1}{ }^{2} \cdot \mathrm{t}_{1}-\frac{\pi}{4} \mathrm{D}_{2}{ }^{2} \cdot \mathrm{t}_{2}\right)+\left(\frac{\pi}{4} \mathrm{D}_{3}{ }^{2} \mathrm{t}_{3}+\frac{\pi}{4} \mathrm{D}_{4}{ }^{2} \cdot \mathrm{t}_{4}+\frac{\pi}{4} \mathrm{D}_{5}{ }^{2} \cdot \mathrm{t}_{5}\right) \\
& =\left(\frac{\pi}{4}(0,27)^{2} \cdot 0,285-\frac{\pi}{4}(0,27)^{2} \cdot 0,15\right) \mathrm{m}^{3}+\left(\frac{\pi}{4}(0,27)^{2}\right. \\
& .0,135+\frac{\pi}{4}(0,08)^{2} \cdot 0,295 \\
& =(0,0163-0,008)+(0,002+0,0077) \\
& =0,018 \mathrm{~m}^{3}=18 \mathrm{dm}^{3}=18 l
\end{aligned}
$$

E2. Volume Fluida Pada Saat Mold Membuka

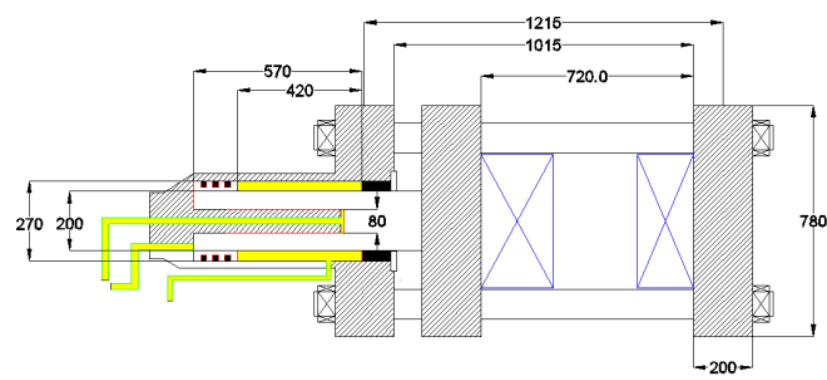

Gambar 6. Aliran Fluida Pada Saat Mold Membuka

$$
\begin{gathered}
\quad \mathrm{V}_{\mathrm{o}}=\left(\frac{\pi}{4} \mathrm{D}_{1}{ }^{2} \cdot \mathrm{t}_{1}-\frac{\pi}{4} \mathrm{D}_{2}{ }^{2} \cdot \mathrm{t}_{2}-\frac{\pi}{4} \mathrm{D}_{3}{ }^{2} \cdot \mathrm{t}_{3}\right) \\
=\left(\frac{\pi}{4}(0,27)^{2} \cdot 0,42-\frac{\pi}{4}(0,2)^{2} \cdot 0,42-\frac{\pi}{4}(0,27)^{2} \cdot 0,15\right) \mathrm{m}^{3} \\
=(0,024-0,013-0,008)=0,003 \mathrm{~m}^{3}=3 \mathrm{dm}^{3}=3 l
\end{gathered}
$$

Dimana:

$$
\begin{aligned}
\mathrm{V}_{\mathrm{c}} & =\text { Volume Close }\left(\mathrm{m}^{3}, \mathrm{dm}^{3}, l\right) \\
\mathrm{V}_{\mathrm{o}} & =\text { Volume Open }\left(\mathrm{m}^{3}, \mathrm{dm}^{3}, l\right) \\
\mathrm{D} & =\text { Diameter Silinder } / \text { Ruang Silinder }(\mathrm{m}) \\
\mathrm{t} & =\text { Tebal } / \text { Panjang Silinder }(\mathrm{m})
\end{aligned}
$$

F. Menghitung Volume Tangki

Volume tangki biasanya 2 hingga 5 kali dari volume fluida dalam silinder yang dibutuhkan. Direncanakan volume tangki 2,5 kali dari $18 l$ yang di butuhkan atau kurang lebih 50 liter, yang mana diperoleh dari rumus [1]:

$$
\begin{aligned}
V & =P \times 1 \times t \\
& =(0,4 \times 0,4 \times 0,3125) \mathrm{m}^{3}=0,05 \mathrm{~m}^{3}=50 \mathrm{dm}^{3}
\end{aligned}
$$




$$
=50 l
$$

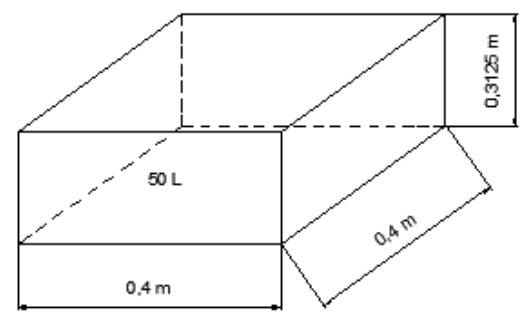

Gambar 7. Volume Tangki

Diketahui:

${ }^{\circ}$ Densitas oli hidrolik VMGZ $=870 \mathrm{~kg} / \mathrm{m}^{3}$

- Volume tangki $=0,05 \mathrm{~m}^{3}$

G. Beban Terpusat Pada Dasar Tangki

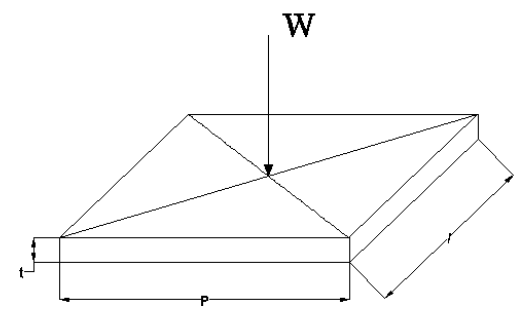

Gambar 8. Penampang Dasar Tangki

$$
\begin{aligned}
\mathrm{P}_{\text {tangki }} & =\rho_{\text {fluida }} \cdot \mathrm{g} \cdot \mathrm{h} \\
& =870 \mathrm{~kg} / \mathrm{m}^{3} \cdot 9,81 \mathrm{~m} / \mathrm{s}^{2} \cdot 0,2475 \mathrm{~m} \\
& =2112,33 \mathrm{~N} / \mathrm{m}^{2} \\
\mathrm{P} & =\frac{F}{A} \\
\mathrm{~F} & =\mathrm{P} . \mathrm{A} \\
& =2112,33 \mathrm{~N} / \mathrm{m}^{2} \cdot 0,4 \mathrm{~m} \cdot 0,4 \mathrm{~m}=337,972 \mathrm{~N} \\
\mathrm{P}_{\text {dasar tangki }} & =\frac{F}{A}=\frac{F}{2 t \mathrm{tl}}=\frac{a m 7,972}{2 \cdot \text { a mm } .400 \mathrm{~mm}}=0,14 \mathrm{~N} / \mathrm{mm}^{2} \\
\text { Dimana: } & \\
\mathrm{P}_{\text {tangki }} & =\text { Tekanan Pada Tangki }(\mathrm{N}) \\
\mathrm{F} & =\text { Gaya Pada Dasar Tangki }(\mathrm{N}) \\
\rho_{\text {fluida }} & =\text { Kerapatan massa fluida }\left(\mathrm{kg} / \mathrm{m}^{3}\right) \\
\mathrm{g} \quad & =\text { Gaya Gravitasi }\left(\mathrm{m} / \mathrm{s}^{2}\right) \\
\mathrm{h} \quad & =\text { Tinggi Fluida }
\end{aligned}
$$

H. Momen Inersia Tangki

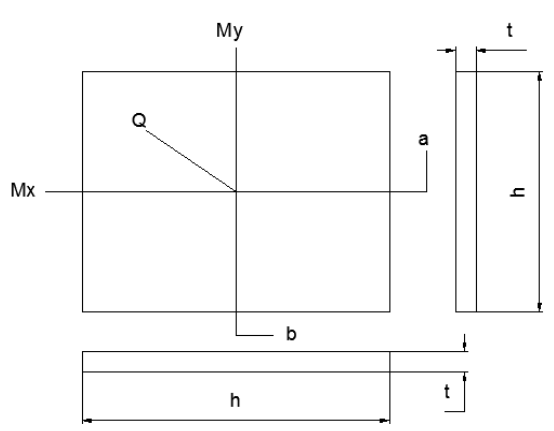

Gambar 9. Penampang Dasar Tangki
Momen searah sumbu x yang terjadi pada dasar tangki dirumuskan:

$$
\begin{aligned}
& \mathrm{Q}=\mathrm{P}_{\text {tangki }} \cdot \mathrm{A} \\
& =2112,33 \mathrm{~N} / \mathrm{m}^{2} \cdot 0,4 \mathrm{~m} \cdot 0,4 \mathrm{~m}=337,972 \mathrm{~N} \\
& \mathrm{M}_{\mathrm{x}}=\frac{\mathrm{Q}}{\mathrm{a}} \\
& =\frac{\operatorname{lng}^{2} 972 \mathrm{~N}}{2} \frac{400 \mathrm{~mm}}{2}=33797,2 \mathrm{Nmm}
\end{aligned}
$$

Momen searah sumbu y yang terjadi pada dasar tangki dirumuskan:

$$
\begin{aligned}
\mathrm{Q} & =\mathrm{P}_{\text {tangki }} \cdot \mathrm{A} \\
& =2112,33 \mathrm{~N} / \mathrm{m}^{2} \cdot 0,4 \mathrm{~m} \cdot 0,4 \mathrm{~m}=337,972 \mathrm{~N} \\
\mathrm{M}_{\mathrm{y}} & =\frac{\mathrm{Q}}{2} \frac{\mathrm{b}}{2} \\
& =\frac{\sqrt{\mathrm{ab}, 972 \mathrm{~N}}}{2} \frac{400 \mathrm{~mm}}{2}=33797,2 \mathrm{Nmm}
\end{aligned}
$$

Dimana :

$\mathrm{Q}=$ Tekanan Hidrostatika $(\mathrm{N})$

$\mathrm{M}_{\mathrm{x}}=$ Momen pada sumbu $\mathrm{x}(\mathrm{Nmm})$

$\mathrm{M}_{\mathrm{y}}=$ Momen pada sumbu y (Nmm)

$\mathrm{a}=$ Panjang searah sumbu $\mathrm{x}(\mathrm{mm})$

$\mathrm{b}=$ Panjang searah sumbu y $(\mathrm{mm})$

Momen total yang terjadi adalah

$$
\begin{aligned}
\mathrm{M}_{\text {Total }} & =\sqrt{M_{x}^{2} \cdot M_{y}^{2}} \\
& =\sqrt{33797,2^{2}+33797,2^{2}} \\
& =47796,45 \mathrm{Nmm}
\end{aligned}
$$

Tegangan yang terjadi pada dasar tangki dirumuskan:

$$
\begin{aligned}
\sigma & =\frac{M}{W}=\frac{47796,45 \mathrm{Nmm}}{\frac{1}{12} \cdot \sqrt[h]{\mathrm{h} \cdot \mathrm{t}^{3}}}=\frac{47796,45 \mathrm{Nmm}}{\frac{1}{6} \cdot \mathrm{h} \cdot \mathrm{t}^{2}} \\
& =\frac{47796,45 \mathrm{Nmm}}{\frac{1}{6} \cdot 400 \cdot\left(\mathrm{a}^{2}\right) \mathrm{mm}^{2}}=79,66 \mathrm{~N} / \mathrm{mm}^{2}
\end{aligned}
$$

Dengan menggunakan spesifikasi pelat 409 dengan kekuatan tarik minimalnya adalah $380 \mathrm{MPa}=380 \mathrm{~N} / \mathrm{mm}^{2}$ dengan tebal pelat $3 \mathrm{~mm}$ dan faktor kemanan 4 .

Tegangan izin pelat $>$ Tegangan pelat yang terjadi $95 \mathrm{~N} / \mathrm{mm}^{2}>79 \mathrm{~N} / \mathrm{mm}^{2}$

I. Menghitung Kapasitas External Gear Pump

I1. Spesifikasi External Gear Pump

1. Pompa tipe PLP = PL 10.1 (Polaris 10.1) Motor tipe PLM

Dimana:

$\mathrm{P}=0,4 \mathrm{~kW}$

$\mathrm{n}=650 /$ menit

$\mathrm{p}=260 \mathrm{bar}(3770 \mathrm{psi})=26 \mathrm{~N} / \mathrm{mm}^{2}$

2. Displacement $=0,07(1,07) \mathrm{in}^{3} / \mathrm{rev}\left(\mathrm{cm}^{3} / \mathrm{rev}\right)$

3. Max Pressure $\mathrm{P}_{1}=3770$ (260) psi (bar)

$$
\mathrm{P}_{2}=4060 \text { (280) psi (bar) }
$$



4. Max Speed
$\mathrm{P}_{3}=4205$ (290) psi (bar) Min Speed $=4000 /$ menit $=650 /$ menit (direncanakan)

Tabel 1. Siklus Pompa dan Daya

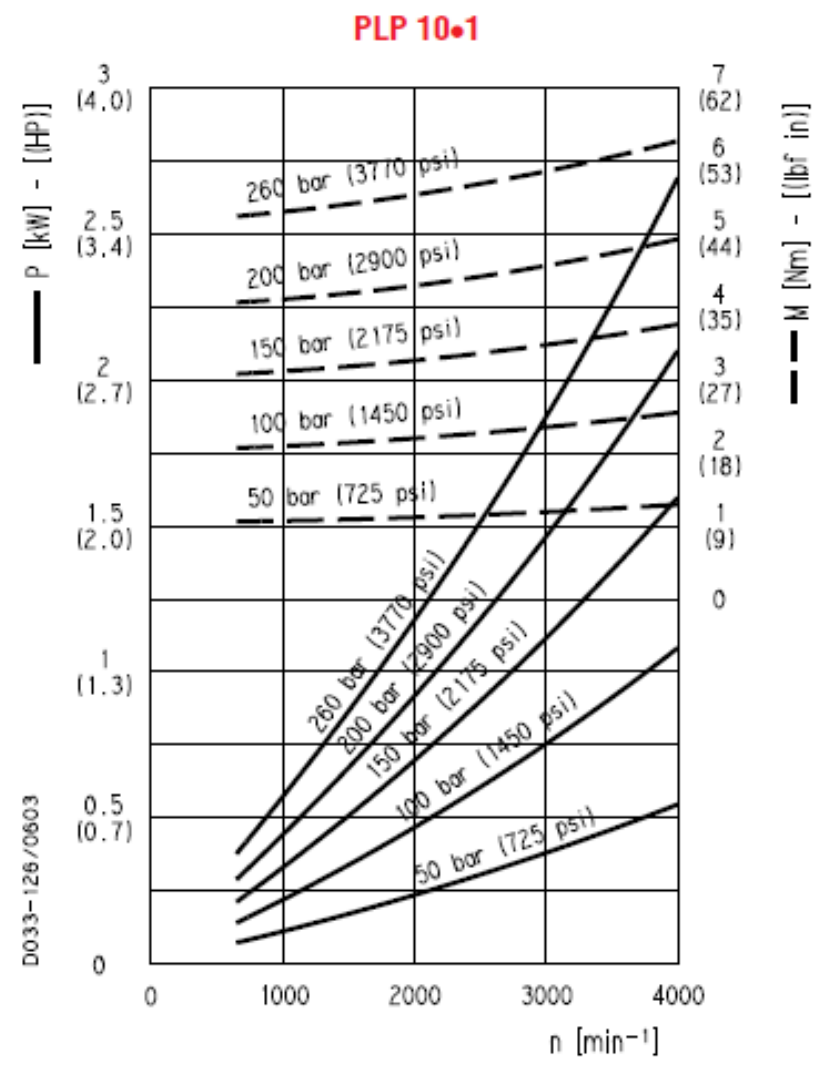

I2. Efisiensi

Berdasar spesifikasi dapat hitung laju aliran fluida per detik dimana dirumuskan sebagai berikut [1]:

$$
\begin{aligned}
\mathrm{Q} & =\text { Displacement } \times \text { Kecepatan } \\
& =1,07 \mathrm{~cm}^{3} / \mathrm{rev} \times 650 / \mathrm{menana} \\
& =695,5 \mathrm{~cm}^{3} / \mathrm{menit}\left(\frac{1 \mathrm{~m}^{3}}{1000 \mathrm{~cm}^{3}}\right)\left(\frac{1 \text { menit }}{60 \mathrm{~s}}\right) \\
& =0,0115 \mathrm{~m}^{3} / \mathrm{s}=11,5 \mathrm{dm}^{3} / \mathrm{s}=11,5 \% \mathrm{~s} \\
\mathrm{Q} & =11,5 \% \mathrm{~s} \eta_{\mathrm{v}} \\
& =11,5 \% \times 0,97=11,155 \%
\end{aligned}
$$

Dimana :

$$
\begin{aligned}
& \mathrm{Q}=\text { Laju Aliran Fluida }\left(\mathrm{m}^{3} / \mathrm{s}\right) \\
& \eta_{\mathrm{v}}=\text { Volumetric Efficiency }
\end{aligned}
$$

Diketahui volume tangki adalah 50, tetapi tangki (gambar 7) juga membutuhkan perbandingan udara dan air sebesar 20\% : 80\% yang dirumuskan:

$$
\begin{aligned}
\mathrm{V} & =\frac{\mathrm{s0}}{100} \times 0,05 \mathrm{~m}^{3}=0,040 \mathrm{~m}^{3} \\
\mathrm{~V}_{\mathrm{u}} & =\mathrm{V}_{\text {tangki kosong }}-\mathrm{V}_{\text {tangki fluida isi }} \\
& =0,05 \mathrm{~m}^{3}-0,04 \mathrm{~m}^{3}=0,01 \mathrm{~m}^{3}
\end{aligned}
$$

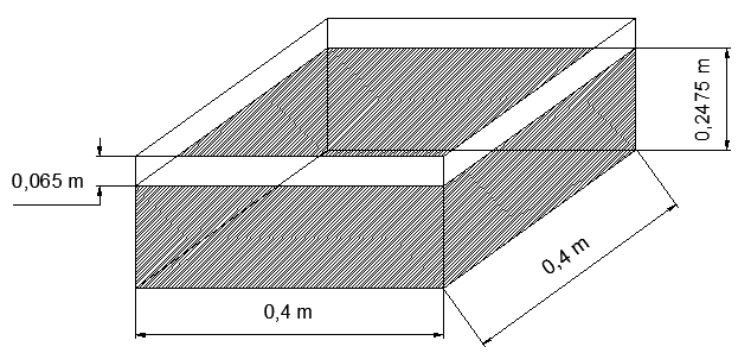

Gambar 10. Perbandingan Volume Tangki dan Udara

$$
\begin{aligned}
\mathrm{V}_{\text {sisa fluida tangki }} & =\mathrm{V}_{\text {fluida isi }}-\mathrm{V}_{\text {fluida terpakai }} \\
& =40 l-33,465 l=6,535 l=0,00653 \mathrm{~m}^{3}
\end{aligned}
$$

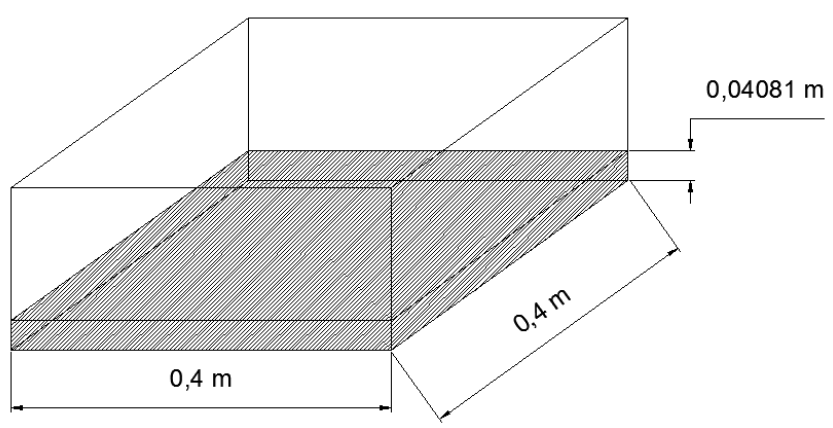

Gambar 11. Volume Tangki Fluida Sisa

J. Menghitung Sistem Kerja Pipa

Hilang tekanan pada aliran fluida penting untuk diketahui dalam merencanakan sistem hidrolik. Kerugian tekanan pada pipa dapat dinyatakan dengan rumus [1]:

$$
\begin{aligned}
h_{L} & =\frac{32 \cdot w \cdot L \cdot V}{g \cdot d^{2}}(\text { Pada Pipa) } \\
& =\frac{a 2 \cdot 0,0000105 \frac{m^{2}}{s} \cdot 2,740 \mathrm{~m} \cdot 0,926 \frac{m}{s}}{9,81 \frac{m}{s^{2}} \cdot 0,0127^{2}} \\
& =\frac{0,000897}{0,00159}=0,481 \mathrm{~m}
\end{aligned}
$$

Dimana :

$$
\begin{aligned}
\mathrm{h}_{\mathrm{L}} & =\text { Kerugian Tekanan }(\mathrm{m}) \\
v & =\text { Viskositas Kinematik }=10,5 \mathrm{~mm}^{2} / \mathrm{s} \\
\mathrm{L} & =\text { Panjang Pipa }(\mathrm{m})(\text { direncanakan }) \\
\mathrm{V} & =\text { Kecepatan Aliran }(\mathrm{m} / \mathrm{s}) \\
\mathrm{g} & =\text { Gaya Gravitasi } \approx 9,81 \mathrm{~m} / \mathrm{s}^{2} \\
\mathrm{~d} & =\text { Diamater Dalam Pipa }(\mathrm{m})
\end{aligned}
$$

$$
\begin{aligned}
\operatorname{Re} & =\frac{V \cdot d}{V} \\
\mathrm{~V} & =\frac{V \cdot R e}{d}=\frac{0,0000105 \mathrm{~m}^{2} / g \cdot 1000}{0,0127 \mathrm{~m}}=0,826 \mathrm{~m} / \mathrm{s}
\end{aligned}
$$

Penurunan Head akibat sambungan, belokan, maupun katup-katup dinyatakan dengan rumus :

$$
\begin{aligned}
\mathrm{h}_{\mathrm{L}} & =\mathrm{k} \frac{V^{2}}{2 \cdot g}(\text { pada Head }) \\
& =\underset{ }{\left(0,5+226^{2}\right.} \\
& \frac{0,9.91}{2 \cdot 9.91} \\
= & 0,782 \mathrm{~m}
\end{aligned}
$$


Dimana :

Belokan $90^{\circ}: \mathrm{k}=0,5$

$$
\mathrm{V}=\text { Kecepatan Aliran }\left(\mathrm{m} / \mathrm{s}^{2}\right)
$$$$
\mathrm{g}=\text { Gaya Gravitasi } \approx 9,81 \mathrm{~m} / \mathrm{s}^{2}
$$

Check Valve $: \mathrm{k}=2$

Flow Control Valve : $\mathrm{k}=5$

Directional Valve $: \mathrm{k}=3$

K. Menghitung Tekanan Dalam Pipa

K1. Spesifikasi Pipa

1. NB (Normal Bore $)=1 / 2$ inch $=12,7 \mathrm{~mm}$

2. OD (Out Diameter) $\quad=21,336 \mathrm{~mm}$

3. $\mathrm{NB}($ Normal Bore $)=1 / 4$ inch $=6,35 \mathrm{~mm}$

4. OD (Out Diameter $)=13,716 \mathrm{~mm}$

5. DIN EN $8532 \mathrm{SN}$ (pipa rubber) $1 / 2$ inch

6. DIN EN $8532 \mathrm{SN}$ (pipa rubber) $1 / 4$ inch

7. $\mathrm{P}_{\text {pompa }}=26 \mathrm{~N} / \mathrm{mm}^{2}$

8. Menghitung Luas Penampang Pada Pipa $1 / 2$ inch

$$
\begin{aligned}
\mathrm{A} & =\frac{\pi}{4}\left(\mathrm{~d}_{\mathrm{o}}{ }^{2}-\mathrm{d}_{\mathrm{i}}^{2}\right) \\
& =\frac{\pi}{4}\left(21,336^{2}-12,7^{2}\right)=230,73 \mathrm{~mm}^{2}
\end{aligned}
$$

9. Menghitung Luas Penampang Pada Pipa $1 / 4$ inch

$$
\begin{aligned}
\mathrm{A} & =\frac{\pi}{4}\left(\mathrm{~d}_{\mathrm{o}}^{2}-\mathrm{d}_{\mathrm{i}}^{2}\right) \\
& =\frac{\pi}{4}\left(13,716^{2}-6,35^{2}\right) \\
& =116,02 \mathrm{~mm}^{2}
\end{aligned}
$$

K2. Tegangan Tarik Searah Aliran Pipa (Longitudinal Stress)

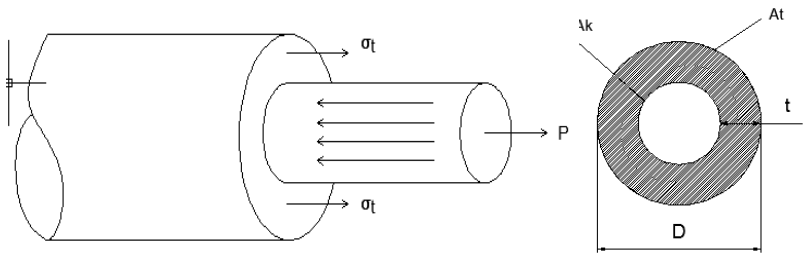

Gambar 12. Penampang Longitudinal Stress

$$
\begin{aligned}
& \sigma_{\mathrm{t}}=\frac{F}{A}=\frac{P \cdot A_{\mathrm{t}}}{A_{\mathrm{k}}}=\frac{P \cdot \frac{\pi}{4} \cdot D^{2}}{\pi, D, t}=\frac{P, D}{4, t}
\end{aligned}
$$

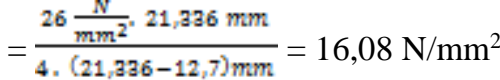

Dimana:

$$
\begin{aligned}
& \sigma_{\mathrm{t}}=\text { Tegangan Tarik }\left(\mathrm{N} / \mathrm{mm}^{2}\right) \\
& \mathrm{F}=\text { Gaya }(\mathrm{N}) \\
& \mathrm{A}_{\mathrm{t}}=\text { Luas Penampang Pipa Tangki }\left(\mathrm{mm}^{2}\right) \\
& \mathrm{A}_{\mathrm{k}}=\text { Luas Penampang Kulit Pipa }\left(\mathrm{mm}^{2}\right) \\
& \mathrm{P}=\text { Tekanan }\left(\mathrm{N} / \mathrm{mm}^{2}\right)
\end{aligned}
$$

\section{K3. Tegangan Tarik Axial (Axial Stress)}

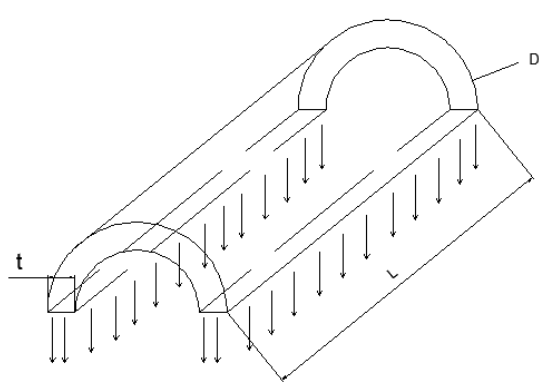

Gambar 13. Axial Stress Pada Pipa

$$
\begin{aligned}
& \sigma_{\mathrm{t}}=\frac{E}{A}=\frac{P, A}{2, \mathbb{D} \cdot \mathrm{t}}=\frac{P, D \cdot \mathbb{D}}{2 \cdot \mathbb{D}, \mathrm{t}}=\frac{P, D}{2, \mathrm{t}} \\
& =\frac{26 \frac{\mathrm{N}}{\mathrm{mm}^{2}}, 21_{1} a 96 \mathrm{~mm}}{2 \cdot\left(21_{1} \mathrm{a} 36-12,7\right) \mathrm{mm}}=32,11 \mathrm{~N} / \mathrm{mm}^{2}
\end{aligned}
$$

Dimana:

$$
\begin{aligned}
\sigma_{\mathrm{t}} & =\text { Tegangan Tarik }\left(\mathrm{N} / \mathrm{mm}^{2}\right) \\
\mathrm{F} & =\operatorname{Gaya}(\mathrm{N}) \\
\mathrm{A} & =\operatorname{Luas} \text { Penampang }\left(\mathrm{mm}^{2}\right)
\end{aligned}
$$

Catatan: besarnya radial stress $=0$ karena terletak pada bagian luar pipa.

\section{KESIMPULAN}

Dari hasil "Perancangan Kerja Sistem Hidrolik Pada Clamping Unit Untuk Mesin Cetakan Injeksi Plastik" data yang diperoleh sebagai berikut:

1. Sistem hidrolik pada clamping unit ini bekerja mulai dari tangki berkapasitas $50 l$ berisi fluida VMGZ dengan viskositas $870 \mathrm{~kg} / \mathrm{mm}^{2}$, kemudian di hisap oleh pompa dengan tekanan $260 \mathrm{bar}=26 \mathrm{~N} / \mathrm{mm}^{2}$.

2. Daya motor $0,4 \mathrm{~kW}$ dan 650 putaran permenit, melalui pipa baja dengan diameter luar OD $=1 / 2$ inch dan diameter dalam $\mathrm{NB}=21,336 \mathrm{~mm}$.

3. Pada saat silinder bersamaan movable platen yang mempunyai berat platen dan mold sebesar 1330,68 $\mathrm{kg}$ bergerak menutup cetakan dengan jarak $680 \mathrm{~mm}$, gaya tekan $850 \mathrm{~N}$ dibagi 4 batang pengikat (tie bar) menjadi 212,5 ton, dan mampu menekan stationery platen dengan gaya tekan balik sebesar 700 ton.

4. Fluida di dalam silinder akan mengisi sebanyak 18,20 l. Pada saat proses membuka cetakan flow control valve akan berubah posisi dimana aliran fluida dari katup melalui pipa baja dengan diameter $\mathrm{OD}=1 / 4$ inch dan $\mathrm{NB}=13,716 \mathrm{~mm}$ yang akan menuju ke aktuator balik dimana fluida volume silinder akan mengisi sebanyak 3,2 $l$ dengan jarak kembali sama yaitu $680 \mathrm{~mm}$, kemudian aliran fluida akan kembali ke tangki hingga seterusnya. 


\section{REFERENSI}

[1] Harinaldi Budiarso, Prinsip Dasar dan Penerapan Fluida, Sistem Hidrolik dan Sistem Pneumatik, Erlangga: Jakarta 2015

[2] Sularso, Dasar Perancangan dan Pemilihan Elemen Mesin, Pradnya Paramitha: Jakarta, 2002 